\title{
On the crossing numbers of Cartesian products of paths with special graphs
}

\section{Marián Klešč, Daniela Kravecová and Jana Petrillová}

\begin{abstract}
.
There are known exact results of the crossing numbers of the Cartesian product of all graphs of order at most four with paths, cycles and stars. Moreover, for the path $P_{n}$ of length $n$, the crossing numbers of Cartesian products $G \square P_{n}$ for all connected graphs $G$ on five vertices and for forty graphs $G$ on six vertices are known. In this paper, we extend these results by determining the crossing numbers of the Cartesian products $G \square P_{n}$ for six other graphs $G$ of order six.
\end{abstract}

Acknowledegment. The research was supported by the Slovak VEGA grant No. 1/0309/11. This work was also supported by the Slovak Research and Development Agency under the contract No. APVV-0008-10.

\section{REFERENCES}

[1] Beineke, L. W. and Ringeisen, R. D., On the crossing numbers of products of cycles and graphs of order four, J. Graph Theory, 4 (1980), 145-155

[2] Bokal, D., On the crossing numbers of Cartesian products with paths, J. Combin. Theory B, 97 (2007) 381-384

[3] Draženská, E. and Klešč, M., The crossing numbers of products of the graph $K_{2,2,2}$ with stars, Carpathian J. Math., 24 (2008), 327-331

[4] Garey, M. R. and Johnson, D. S., Crossing number is NP-complete, SIAM J. Alg. Discrete. Discr. Meth., 4 (1983), 312-316

[5] Hliněný, P., Crossing number is hard for cubic graphs, J. Comb. Theory Ser. B, 96 (2006), 455-471

[6] Jendrol', S. and Ščerbová, M., On the crossing numbers of $S_{m} \times P_{n}$ and $S_{m} \times C_{n}$, Časopis pro pěstování matematiky, 107 (1982), 225-230

[7] Klešč, M., The crossing numbers of Cartesian products of stars and paths or cycles, Mathematica Slovaca, $4 \mathbf{1}$ (1991), 113-120

[8] Klešč, M., The crossing numbers of products of paths and stars with 4-vertex graphs, J. Graph Theory, 18 (1994), 605-614

[9] Klešč, M., The crossing numbers of products of 4-vertex graphs with paths and cycles, Discuss. Math Graph Theory, 19 (1999), 59-669

[10] Klešč, M., The crossing numbers of Cartesian products of paths with 5-vertex graphs, Discrete Math., 233 (2001), 353-359

[11] Klešč, M. and Petrillová, J., On Cartesian products with small crossing numbers, Carpathian J. Math., 28 (2012), 67-75

[12] Klešč, M. and Petrillová, J., The crossing numbers of products of path with graphs of order six, Discuss. Math Graph Theory, 33 (2013), 571-582

[13] Klešč, M. and Schrötter Š., On the crossing numbers of Cartesian products of stars and graphs of order six, Discuss. Math Graph Theory, 33 (2013), 583-597

[14] Kravecová, D., The crossing number of $P_{5}^{2} \times P_{n}$, Creative Mathematics and Informatics, 21 (2012), 65-72

[15] Leighton, F. T., Complexity issues in VLSI, M.I.T. Press, Cambridge, 1983

[16] Ouyang, Z. D., Wang, J. and Huang Y. Q., The crossing number of the Cartesian product of paths with complete graphs, Discrete Math., 328 (2014), 71-78

Received: 08.11.2013; In revised form: 09.09.2014; Accepted: 20.10.2014

2010 Mathematics Subject Classification. 05C10, 05C38.

Key words and phrases. Cartesian product, crossing number, drawing, graph, path.

Corresponding author: Daniela Kravecová; daniela.kravecova@tuke.sk 
[17] Peng, Y. H. and Yiew, Y. C., The crossing number of $P(3,1) \times P_{n}$, Discr. Math., 306 (2006), 1941-1946

[18] Ringeisen, R. D. and Beineke, L. W., The crossing number of $C_{3} \square C_{n}$, J. Combinatorial Theory, 24 (1978), 134-136

[19] Wang, J. and Huang, Y., The crossing number of $K_{2,4} \times P_{n}$, Acta Math. Sci., Ser A, Chin Ed., 28 (2008), 251-255

[20] Zheng, W., Lin, X., Yang, Y. and Cui, Ch., On the crossing number of $K_{m} \square P_{n}$, Graphs Combin., 23 (2007), $327-336$

TECHNiCAl UNiVERSITY OF KošICE

FACULTY OF ELECTRICAL ENGINEERING AND INFORMATICS

DEPARTMENT OF MATHEMATICS AND THEORETICAL INFORMATICS

NĚMCOVEJ 32, 042 00, Košice, SLOVAKIA

E-mail address: marian.klesc@tuke.sk

E-mail address: daniela.kravecovaetuke.sk

E-mail address: jana.petrillova@tuke.sk 